Relations industrielles

Industrial Relations

\title{
The Liability of Strikes in the Law of Tort (a comparative study of the law in England and Canada), by I.M. Christie, Industrial Relations Centre, Queen's University, Kingston, Ontario, 1967, 198 pp.
}

\section{André Petit}

Volume 23, numéro 1, 1968

URI : https://id.erudit.org/iderudit/027878ar

DOI : https://doi.org/10.7202/027878ar

Aller au sommaire du numéro

Éditeur(s)

Département des relations industrielles de l'Université Laval

ISSN

0034-379X (imprimé)

1703-8138 (numérique)

Découvrir la revue

Citer ce compte rendu

Petit, A. (1968). Compte rendu de [The Liability of Strikes in the Law of Tort (a comparative study of the law in England and Canada), by I.M. Christie, Industrial Relations Centre, Queen's University, Kingston, Ontario, 1967, 198 pp.] Relations industrielles / Industrial Relations, 23(1), 180-180. https://doi.org/10.7202/027878ar

Tous droits réservés @ Département des relations industrielles de l'Université Laval, 1968
Ce document est protégé par la loi sur le droit d'auteur. L'utilisation des services d'Érudit (y compris la reproduction) est assujettie à sa politique d'utilisation que vous pouvez consulter en ligne.

https://apropos.erudit.org/fr/usagers/politique-dutilisation/ 
du Canoda et c'est l'éducation, ou plutôt les différents systèmes éducationnels.

En conclusion, il souligne que peu de recherches ont été orientées du côté d'un facteur qui lui semble capital: la propriété étrangère d'une bonne partie de notre économique. L'auteur insiste sur la nécessité de poser un jugement dénué de tout préjugé nationaliste ou autre sur cette question fondamentale, ofin de déterminer la politique notionale la mieux appropriée à la situotion.

\section{Jean BOIVIN}

The Liability of Strikes in the Law of Tort (a comparative study of the law in England and Canada), by I.M. Christie, Industrial Relations Centre, Queen's University, Kingston, Ontario, 1967, 198 pp.

L'aspect juridique, dans le domaine des relations industrielles, a une importance indéniable. Aux yeux du public en général, c'est même cet aspect qui peut sembler le plus important en raison d'abord de l'intervention de plus en plus grande de l'Etat dans les conflits de travail et aussi en raison de cette sorte de mystère dont s'entoure tout ce qui s'appelle droit, jurisme, lois, responsabilités, dommages, injonctions, etc.

Ces dernières années, le recours à l'injonction, soit par l'Etat, soit par des intérêts privés et les imbroglios qui en ont découlé ont contribué à amplifier encore plus cette impression. En Ontario, par exemple, les activités syndicales à Oshawa et à Peterborough ont attiré l'attention publique sur le résultat d'injonctions contre le piquetage et ont conduit à la création de la Commission Rand

Cette étude ne traite pas directement du problème de I'injonction; elle constitue plutôt une étude comparée sur le développement par les cours de justice de nouveaux sujets de responsabilités en dommages pour les grévistes.

Le chapitre I traite du problème de façon générale et tente de mettre en perspective le développement de la loi en regard des lois statutaires et des attitudes des cours de justice par rapport aux activités syndicales en Angleterre et ou Canada.

Les chapitres II, III, IV et V touchent encore l'évolution des lois dans les deux pays mais étudient plus précisément le développement des sujets suivants: les restrictions statutaires sur le piquetage, la responsabilité civile en matière de conspiration, l'incitotion au bris de contrat dans les conflits de travail et, la responsabilité en cas d'interférences avec les droits de commercer et de gagner sa vie.

En guise de conclusion, l'outeur indique de quelle façon, selon lui, certaines des lois concernées devraient évoluer dans les prochaines années.

\section{André PETIT}

\section{Les Devoirs des dirigeants de sociétés par} actions, par Marc Giguère, Presses de I'Université Loval, Québec, 1967, 245 pp

Dans les relations complexes qui existent entre le droit et l'économie, l'auteur apporte un éclaircissement valable qui tient compte à la fois des évolutions récentes des cadres juridiques et administratifs, et des confrontations des règles de droit anglaises, françaises, canadiennes et québecoises. Aux différentes règles de droit, il ajoute des interprétations et des normes, les plus communément admises oujourd'hui par les odministrateurs des sociétés par actions.

Marc Giguère prend pour acquise la division maintenant classique entre le pouvoir et la propriété. C'est surtout cette division qui le concerne, mais au moment où elle s'affronte aux vieilles politiques de gestion. En effet, si l'auteur nous propose des champs beaucoup plus vastes de répercussion de cette division, il nous ramène très vite à des problèmes très techniques qui se posent davantage en termes de nouvelles relations à établir entre les nouveaux et les anciens détenteurs d'un pouvoir qui échappe toujours à la société, plus précisément aux consommateurs et aux employés qui s'expriment par les pouvoirs publics. Cet ouvrage s'adresse plus aux vérificateurs et aux comptables donc, moins oux personnes concernées et intéressées dans un nouveau partage du pouvoir, dans un nouveou pouvoir même.

Dans cet ordre d'idée, l'auteur discute, par le moyen du droit comparé, les limites du pouvoir des dirigeants, les finalités de la gestion. II pose les difficultés d'appréciation de la compétence, de la diligence et de l'habileté. II nous entraîne dans les détours que poursuit la gestion en tentant de définir les pratiques intègres, permises ou non par les nouveaux détenteurs du pouvoir. Ces explications sont d'un ordre trop particulier pour être comprises par des gens qui ne sont pas très familiers avec ces milieux-là. 